\title{
Mothers' Knowledge Regarding Preventive Measures of Food Poisoning in Yemen
}

\author{
Waled Amen Mohammed Ahmed \\ Faculty of Applied Medical Sciences, Albaha University, Al-Baha, Saudi Arabia \\ Email: weliameen1980@yahoo.com
}

Received 13 November 2014; revised 9 December 2014; accepted 17 December 2014

Copyright (C) 2015 by author and Scientific Research Publishing Inc.

This work is licensed under the Creative Commons Attribution International License (CC BY). http://creativecommons.org/licenses/by/4.0/

(c) (i) Open Access

\begin{abstract}
Background: The WHO considers food poisoning the main cause of morbidity and mortality in developing countries, and the responsible for high levels of loss of productivity in developed countries. Objective: The study aims to assess the mothers' knowledge about preventive measures of food poisoning in Sharaab, Taiz, Yemen. Method: This is a descriptive study. It was conducted in Sharaab, Yemen during period extended from April to November 2014. It involved 180 mothers selected by simple random sampling. Data were collected by using designed structured and pretested questionnaire and then were analyzed by (SPSS) Version 20. Result: The findings showed that $60 \%$ of mothers have heard about food poisoning. The mothers' knowledge about transmission of diseases by food was acceptable; $68.9 \%$ knew. When they were asked to detail the diseases, cholera was the most reported by about $84.4 \%$, diarrhea $50 \%$, and food poisoning $22.2 \%$ only. Regarding the mothers' knowledge about causes of food poisoning, about $65.5 \%$ of them mentioned contaminated food, and $\mathbf{4 9 . 4 \%}$ mentioned contaminated hands while $37.2 \%$ of them mentioned contaminated utensils. The total knowledge was calculated; it was about $40.72 \%$. Conclusion: It was found that, mothers' knowledge about preventive measures of food poisoning is not satisfactory concerning most items including: food related diseases, causes of food poisoning and preventive measures for food poisoning such as hand washing, washing vegetables and cooking appropriately. The mothers in Yemen, Taiz, Sharaab have low level of knowledge about food poisoning prevention. There is a need for strengthening the situation through educational sessions.
\end{abstract}

\section{Keywords}

Food Poisoning, Mothers, Knowledge Level, Preventive Measures

\section{Background}

Since the first reported cases of food-borne poisoning in the late 18th century, food poisoning has gained atten- 
tion not only as a threat to food producers and consumers but also as a potential cause of crib death of small babies, as a deadly trip for intravenous drug abusers, and as an inspiration for bioterrorists. The occurrence of the food borne diseases and out breaks has serious danger if the hygiene is not maintained properly. The term food borne diseases implies that a disease is usually either infectious or toxic in nature, caused by agents that enter into the body through the ingestion of food. In the recent years, a number of comprehensive reviews on staphylococcal food poisoning and on the staphylococcal enterotoxins have been published and indicated high spread of the disease [1].

Food usually becomes contaminated from poor sanitation or preparation. Food handlers who do not wash their hands after using the bathroom or have infections themselves often cause contamination. Improperly packaged food stored at the wrong temperature also promotes contamination [2]. Food poisoning has an impact on human welfare. The World Health Organization reported it as one of the main cause for morbidity and mortality in developing countries. WHO identifies foodborne disease outbreaks and incidents, including those arising from natural, accidental and deliberate contamination of food, as major global public health threats in the 21st Century [3].

However, the food poisoning is very contagious disease. It has many preventive measures which could be applied. The preventive measures include food hygiene, personal hygiene and washing vegetable and fruits. Bacteria cannot be seen, smelled, or tasted, and they may be on any food. These threats require urgent action [4].

Surveillance of food borne disease outbreaks is fairly well established in developed countries. Even then, only about $10 \%$ of actual cases in industrialized countries are recorded in official statistics. In case of developing countries, it could be even less than $1 \%$ [5].

Although there are a limited number of studies on mothers' knowledge about food poisoning, the present study is unique in several ways: first, touching many populations whose prepare food; second, the importance and effectiveness of preventive measures in our daily life to promote the health; third, this research identifies key determinants of mothers' knowledge, rather than simply documenting what mothers should do. The findings have implications for increasing mothers' awareness and then the practices in their house surroundings.

This study, therefore, aims at assessing mothers' knowledge about preventive measures of food poisoning in Yemen, Taiz, Sharaab. The information gathered is expected to help plan and implement a comprehensive package for preventing food poisoning.

\section{Methods}

This was a descriptive study. It was conducted in Yemen, Taiz, Sharaab.

This study was conducted in Yemen, Taiz, Sharaab. Sharaab area is located at Taiz Province in South of Yemen. There are about 890 houses in this area. The study started in April, 2014 and ended by November, 2014.

The populations of this research study consisted of all mothers in Yemen, Taiz, Sharaab. This study targeted all mothers who live in Yemen, Taiz, Sharaab at the time of study. The target populations were 500 mothers who were then randomized in one list by numbers from 1 to 500. From this list the required sample size was selected.

All mothers in Sharaab are included in this study. The participation in the study was voluntary. It excluded mothers are not resident in study area, who reject to participate in the study, or who have disabilities or handicaps.

The sampling type used was simple random sampling method; by using lottery to select 180 mothers which is the calculated sample size.

A pre-coded, pretested, designed structured questionnaire prepared by researcher under guidance of the supervisor was used to collect the data.

The collected data has been cleaned at the data collection field, organized into a master sheet, and then entered into the computer, using the software Statistical Package for Social Sciences (SPSS) Version 20, in order to be analyzed according to the objectives. All variables have been displayed as frequency tables, charts and graphs. The results have been discussed and compared with expected figures and rates through previous, national and regional studies.

\section{Results Summary}

The study was conducted among 180 mothers in Yemen, Taiz, Sharaab. The participants' demographic charac- 
teristics are described in Table 1 . The table reflects that, $61 \%$ of participants were unemployed, and many of them have at least school education $95.6 \%$, and mean age of participants was 35 years. The cleanliness of kitchen at houses in Yemen, Taiz, Sharaab was poor, since only $42.2 \%$ of them have a cleaned kitchen.

The level of mothers' knowledge about food poisoning is presented in Table 2. It was found that $60 \%$ of mothers have heard about food poisoning. Their knowledge about the diseases could be transmitted by food was acceptable, $68.9 \%$ mentioned they know. When they were asked to detail the diseases, cholera was the most reported by about $84.4 \%$, diarrhea $50 \%$, and food poisoning $22.2 \%$ only. The preventive measures mentioned include: hand washing by $37.2 \%$, washing vegetables by $31.1 \%$ and appropriate cooking by $23.9 \%$. Regarding the mothers' knowledge about causes of food poisoning, about $65.5 \%$ of them mentioned contaminated food, $49.4 \%$ mentioned contaminated hands while $37.2 \%$ of them mentioned contaminated utensils. The total knowledge was calculated; it was about $40.72 \%$.

\section{Discussion}

Recently, food poisoning became one of the common prevailing problems in Yemen. The prevention of food poisoning is human attitude and behaviour which is better than cure. Mothers in houses are more contact to food preparation and cooking, they have to be aware about the diseases could be transmitted through food and the methods to prevent the transmission.

This study is unique in matter that, food poisoning is neglected in developing countries; it also will provide a base for coming further studies.

The study findings showed, their age was about $35 \pm 3.2$ years. They mainly have acceptable educational level comparing to national and regional standards. Most of them have no clean kitchen, because of low socioeconomic status.

Table 1. Characteristics of surveyed mothers in Sharaab, Yemen.

\begin{tabular}{|c|c|}
\hline $\begin{array}{c}\text { Variable } \\
\text { Total }(n=180)\end{array}$ & n (\%) \\
\hline \multicolumn{2}{|l|}{ Employment status } \\
\hline Employed & 70 (38.89\%) \\
\hline Unemployed & $110(61.1 \%)$ \\
\hline \multicolumn{2}{|l|}{ Level of education } \\
\hline Illiterate & 18 (10\%) \\
\hline Primary & 38 (21.1\%) \\
\hline Secondary & 60 (38.9\%) \\
\hline University & $64(33.33 \%)$ \\
\hline \multicolumn{2}{|l|}{ Economic status } \\
\hline Good & 27 (15\%) \\
\hline Fair & 97 (53.9\%) \\
\hline Poor & 56 (31.1\%) \\
\hline \multicolumn{2}{|l|}{ Kitchen cleanliness } \\
\hline Yes & $76(42.2 \%)$ \\
\hline No & $104(57.8 \%)$ \\
\hline \multicolumn{2}{|l|}{ Age } \\
\hline Mean & 35 \\
\hline Std. deviation & 3.2 \\
\hline Minimum & 18.00 \\
\hline Maximum & 43.00 \\
\hline
\end{tabular}


Table 2. Mothers' knowledge about food poisoning in Sharaab, Yemen.

\begin{tabular}{|c|c|c|c|c|}
\hline No. & $\begin{array}{l}\text { Item } \\
\text { Total }(n=180)\end{array}$ & & Freq. & Percent \\
\hline \multirow{2}{*}{1} & \multirow{2}{*}{ Mothers who heard about food poisoning. } & Yes & 108 & $60 \%$ \\
\hline & & No & 72 & $40 \%$ \\
\hline \multirow{2}{*}{2} & \multirow{2}{*}{ Mothers know that; diseases could be transmitted by food. } & Yes & 124 & $68.9 \%$ \\
\hline & & No & 56 & $31.1 \%$ \\
\hline \multirow{4}{*}{3} & \multirow{4}{*}{ Mothers' knowledge about food-related diseases. } & Diarrhea & 90 & $50.0 \%$ \\
\hline & & Cholera & 152 & $84.4 \%$ \\
\hline & & Food poisoning & 40 & $22.2 \%$ \\
\hline & & Dysentery & 35 & $19.4 .0 \%$ \\
\hline \multirow{3}{*}{4} & \multirow{3}{*}{$\begin{array}{l}\text { Mothers' knowledge about preventive measures for } \\
\text { food-poisoning. }\end{array}$} & Hand washing & 67 & $37.2 \%$ \\
\hline & & Washing vegetables & 56 & $31.1 \%$ \\
\hline & & Appropriate cooking & 43 & $23.9 \%$ \\
\hline \multirow{3}{*}{5} & \multirow{3}{*}{ Mothers' knowledge about causes of food poisoning. } & Contaminated food & 118 & $65.5 \%$ \\
\hline & & Contaminated hands & 89 & $49.4 \%$ \\
\hline & & Contaminated utensils & 67 & $37.2 \%$ \\
\hline \multicolumn{3}{|c|}{ Average total mothers' knowledge about food poisoning in Sharaab, Yemen. } & & $40.72 \%$ \\
\hline
\end{tabular}

\section{Conclusions}

It is found that, most mothers are lacking knowledge about diseases that could be transmitted by food such as food poisoning, cholera, diarrhea, and dysentery. These findings are similar to the findings from the study conducted in Italy to investigate the consumers' knowledge, attitude and related behaviour concerning food borne diseases and food-handling practices. This study is similar to findings from the study conducted in Italy which showed that only $11.1 \%$ correctly indicated six related different food vehicles; education level was a predictor of this knowledge, since the educational level of mothers was a factor influencing the level of mothers' knowledge about food poisoning [6].

Concerning the preventive measures that could mitigate the food poisoning transmission such as the hand washing, washing vegetables, and appropriate cooking, the study shows that, they have low level of knowledge. However, most of mothers in Sharaab are educated, while the findings reflect poor knowledge about food poisoning preventive measures. The findings from this study are in contrast to the finding from the study conducted in Nigeria which showed that, the mothers' education was predictor for food poisoning mothers' knowledge [7]. A survey was conducted to investigate knowledge, attitudes and related behavior on food-borne diseases, and food-handling practices among consumers in one region of Italy were also reflected similar results.

\section{Acknowledgements}

The researcher would like to express the sincerest gratitude, indebtedness and appreciation to all mothers participated in this study for their cooperation that made this study possible.

\section{Author's Contributions}

Dr. Waled Amen Mohammed Ahmed, Ph.D., was the main investigator of this study. He is responsible for all steps of study. 


\section{References}

[1] Department of Food and Environmental Hygiene, University of Helsinki (2006) Laboratory Diagnostics of Botulism, American Society of Microbiology. Helsinki, Finland.

[2] Cunha, J.P. (2012) FACOEP D: Food Poisoning. eMedicine Health.

[3] Olea, A., Díaz, J., Fuentes, R., Vaquero, A. and García, M. (2012) Foodborne Disease Outbreaks Surveillance in Chile. Revista Chilena de Infectología, 29, 504-510. http://dx.doi.org/10.4067/S0716-10182012000600004

[4] WHO (2012) Food Safety Issues; Guidance for Establishing and Strengthening Prevention and Response Systems. Department of Food Safety, Geneva.

[5] WHO (1990) World Statistical Report.

[6] Angelillo, I.F., Foresta, M.R., Scozzafava, C. and Pavia, M. (2001) Consumers and Foodborne Diseases: Knowledge, Attitudes and Reported Behavior in One Region of Italy. International Journal of Food Microbiology, 64, 161-166. http://dx.doi.org/10.1016/S0168-1605(00)00451-7

[7] Oladepo, O., Oyejide, C.O. and Oke, E.A. (1991) Training Field Workers to Observe Hygiene-Related Behaviour. World Health Forum, 12, 472-475. 
Scientific Research Publishing (SCIRP) is one of the largest Open Access journal publishers. It is currently publishing more than 200 open access, online, peer-reviewed journals covering a wide range of academic disciplines. SCIRP serves the worldwide academic communities and contributes to the progress and application of science with its publication.

Other selected journals from SCIRP are listed as below. Submit your manuscript to us via either submit@scirp.org or Online Submission Portal.
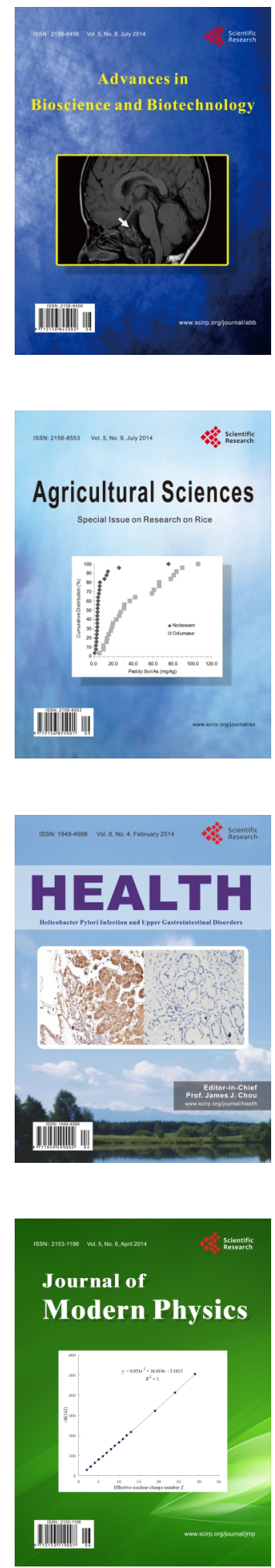
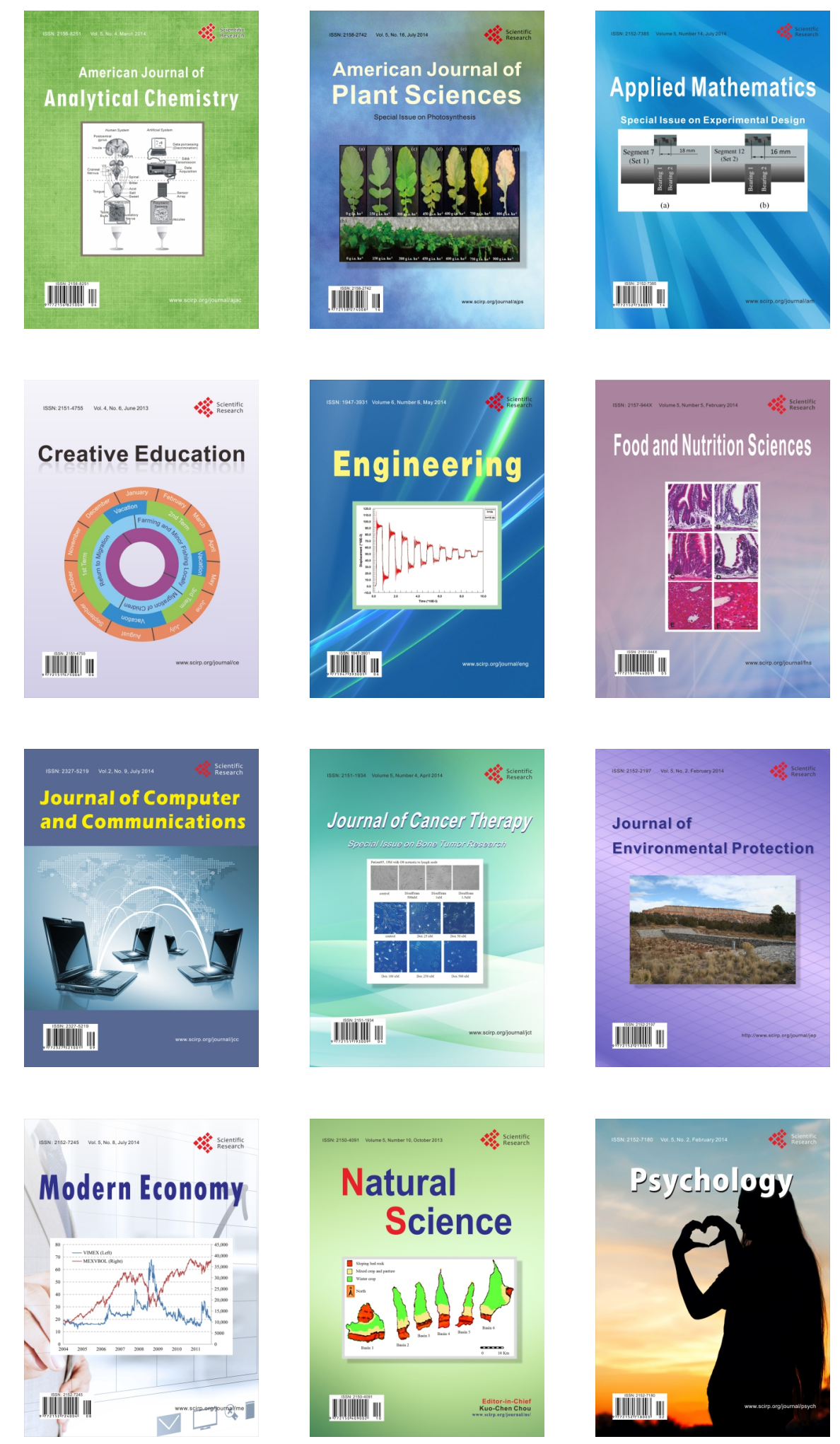